\title{
A Host-Controlled, Serogroup-Specific, Ineffective- Nodulation System in the Bradyrhizobium-Soybean (Glycine max) Symbiosis
}

\author{
David L. Pazdernik, ${ }^{1}$ Carroll P. Vance, ${ }^{1,2}$ Michael J. Sadowsky, ${ }^{3}$ Peter H. Graham, ${ }^{3}$ and James H. Orf ${ }^{1}$ \\ ${ }^{1}$ Department of Agronomy and Plant Genetics, 411 Borlaug Hall, University of Minnesota, St. Paul 55108, \\ U.S.A.; ${ }^{2}$ USDA-ARS, 411 Borlaug Hall, University of Minnesota, St. Paul 55108, U.S.A.; and ${ }^{3}$ Department \\ of Soil, Water, and Climate, 439 Borlaug Hall, University of Minnesota, St. Paul 55108, U.S.A. \\ Accepted 14 July 1997.
}

We have previously reported a soybean plant introduction, PI 437153A, which was ineffectively nodulated (definition of G. Vest, D. F. Weber, and C. Sloger, Agronomy 16:353390, 1973) by Bradyrhizobium japonicum strain UMR (University of Minnesota Rhizobium) 161. In this study, we further characterize this nodulation system by (i) examining the nodulation of $21 \mathrm{~B}$. japonicum strains, representing 15 serogroups, with PI 437153A, (ii) ascertaining the inheritance of the ineffective nodulation, and (iii) characterizing the symbiosis both morphologically and physiologically. Only USDA 126 (serogroup 125) and UMR 161 failed to produce effective nodules with PI 437153A. Segregation among $F_{2}$ and $F_{3}$ plants from a cross between cv. Lambert and PI 437153A was consistent with control of this trait by a single, dominant gene. In reciprocal grafts between cv. Lambert and PI 437153A, ineffective nodulation was determined by the root genotype, and was independent of plant growth temperature and inoculant concentration. The nodule dry weight of UMR 161-inoculated plants of PI 437153A plants was approximately 10 -fold less than that of comparable plants inoculated with USDA 110; nodule soluble protein levels were also significantly reduced. Nitrogenase activity and leghemoglobin could not be detected in the ineffectively nodulated phenotype, but 1 to 6 days after inoculation (DAI) phenylalanine ammonialyase RNA level was higher in the ineffectively nodulated phenotype than in the effectively nodulated one. Microscopic examination of effective and ineffective nodules 20 and 35 DAI revealed major morphological differences. Ineffective nodules contained large, deteriorating regions near apparently infected plant cells at 35 DAI, and schlerenchyma cells that were stained red, suggestive of lignin deposition. These changes could be the result of incompatibility between host and Bradyrhizobium, though the lack of chalcone synthase expression and the appearance

Corresponding author: Peter Graham, Department of Soil, Water, and Climate, 439 Borlaug Hall, University of Minnesota, St. Paul 55108, U.S.A. Telephone: (612) 625-8268; Fax: (612) 625-2208; E-mail:pgraham@soils.umn.edu

This article is in the public domain and not copyrightable. It may be freely reprinted with customary crediting of the source. The American Phytopathological Society, 1997. of infected cells within the ineffective nodules suggest that some later steps in the infection process do occur.

Increased fixation of atmospheric $\mathrm{N}_{2}$ by the Bradyrhizobium-soybean (Glycine max (L.) Merr.) symbiosis decreases the need for commercial application of $\mathrm{N}$ fertilizer and reduces the risk of environmental pollution. Unfortunately, in the U.S. Midwest, indigenous Bradyrhizobium strains dominate nodule formation by soybean, with improved inoculant strains producing only 5 to $15 \%$ of the nodules formed (Johnson et al. 1965; Ham 1978; McDermott and Graham 1989). The result is that the plant may derive less than $50 \%$ of its annual nitrogen needs from symbiosis. One possible solution suggested for this problem is the use of soybean genotypes that nodulate only with specific inoculant strains (Cregan and Keyser 1986).

Several studies have described host genes controlling nodulation response in the Bradyrhizobium-soybean symbiosis. $\mathrm{Rj}_{2}, \mathrm{Rj}_{3}$, and $\mathrm{Rj}_{4}$ are single, dominant genes that condition a restricted nodulation phenotype by strains in serogroups 122 and c1, USDA 33, and USDA 61, respectively (Caldwell 1966; Vest 1970; Vest and Caldwell 1972; Pracht et al. 1993). Allelism tests have established that these three genes are not linked and are located at three distinct loci (Devine and O'Neill 1989, 1993). Two single, recessive genes ( $\mathrm{rj}_{1}$ and $\mathrm{rj}_{6}$ ) and one single, dominant gene $\left(\mathrm{Rj}_{5}\right)$ condition a restricted nodulation phenotype with all bradyrhizobia (Williams and Lynch 1954; Pracht et al. 1993). In other studies, several soybean plant introduction (PI) genotypes and cultivars show a restricted nodulation phenotype with isolates of serogroup 123, USDA 430, USDA 129, and USDA 110 (Cregan and Keyser 1986; Cregan et al. 1989; Sadowsky and Cregan 1992; Ferrey et al. 1994; Lohrke et al. 1995). A single, recessive gene in soybean PI 417566 conditions restriction of nodulation by B. japonicum strain USDA 110 (Lohrke et al. 1996).

While a number of studies have detailed these host-strain interactions and examined the genetics of restriction, few have published in-depth data on nodule morphology, or considered the factors affecting restriction. Nonnodulation in G. $\max \mathrm{cv}$. Bragg and strain-specific restricted nodulation in $G$. $\max \mathrm{cv}$. Hardee, PI 377578, and PI 417566 are root controlled (Caldwell 1966; Delves et al. 1986; Sadowsky et al. 1995); in 
the PI accessions, nodulation is also dependent on plant growth temperature. In pea (Pisum sativum L.), the symbiotic mutant Risfix V hypernodulates, and cells in the late symbiotic zone collapse after differentiation, resembling defense necrosis (Novak et al. 1995). Two plant defense enzymes, phenylalanine ammonia-lyase (PAL) and chalcone synthase (CHS), are also specifically induced in soybean roots following inoculation with $B$. japonicum (Estabrook and SenguptaGopalan 1991), and in the supernodulating mutant nts 382 are expressed at higher levels than in the wild-type parent.

A better understanding of abnormal nodulation in soybean could improve our understanding of symbiosis, and lead to increased $\mathrm{N}_{2}$ fixation. In this paper we examine the ineffective nodulation of PI 437153A with selected strains of B. japonicum (Pazdernik et al. 1996), (i) evaluating the nodulation reaction of 21 Bradyrhizobium strains, representing 15 serogroups, with PI 437153A, (ii) ascertaining the mode of inheritance of this abnormal nodulation, and (iii) characterizing abnormal nodules morphologically and physiologically.

\section{RESULTS}

\section{Nodulation reaction of 21 Bradyrhizobium strains with two soybean genotypes.}

Nineteen of the 21 Bradyrhizobium strains evaluated showed normal nodulation with both cv. Lambert and PI 437153A (Table 1). However, both USDA 126 and UMR (University of Minnesota Rhizobium) 161 produced normal nodules with cv. Lambert, but numerous small, white, ineffec-

Table 1. Nodule dry weight (NDW) and nodule number (No.) of two soybean genotypes inoculated with 21 Bradyrhizobium japonicum and B. elkanii strains harvested 35 days after inoculation ${ }^{\mathrm{x}}$

\begin{tabular}{|c|c|c|c|c|c|}
\hline \multirow[b]{3}{*}{ Strain } & \multirow[b]{3}{*}{ Serogroup } & \multicolumn{4}{|c|}{ Soybean genotype } \\
\hline & & \multicolumn{2}{|c|}{ cv. Lambert } & \multicolumn{2}{|c|}{ PI 437153A } \\
\hline & & $\begin{array}{c}\text { NDW } \\
\text { (mg) }\end{array}$ & No. & $\begin{array}{c}\text { NDW } \\
(\mathbf{m g})\end{array}$ & No. \\
\hline USDA 4 & 4 & $108 \mathrm{cde}^{\mathrm{y}}$ & $37 \mathrm{abcd}$ & $116 \mathrm{abc}$ & $38 \mathrm{~cd}$ \\
\hline USDA 28 & 123 & $118 \mathrm{abc}$ & $40 \mathrm{ab}$ & $118 a b c$ & $40 \mathrm{bcd}$ \\
\hline USDA 33 & 31 & $118 \mathrm{abc}$ & 37 abcd & $120 a b c$ & $44 \mathrm{bcd}$ \\
\hline USDA 44 & 6 & $125 \mathrm{ab}$ & $41 \mathrm{ab}$ & $118 a b c$ & $43 \mathrm{bcd}$ \\
\hline USDA 46 & 46 & $104 \mathrm{cde}$ & 34 bcde & $114 a b c$ & $37 \mathrm{~d}$ \\
\hline USDA 61 & 31 & $115 \mathrm{bcd}$ & 35 bcde & $120 a b c$ & $41 \mathrm{bcd}$ \\
\hline USDA 62 & 62 & $108 \mathrm{cde}$ & $31 \mathrm{cde}$ & $106 \mathrm{c}$ & $39 \mathrm{bcd}$ \\
\hline USDA 94 & 94 & $105 \mathrm{cde}$ & $30 \mathrm{de}$ & $103 \mathrm{c}$ & $37 \mathrm{~d}$ \\
\hline USDA 110 & 110 & $128 \mathrm{ab}$ & $40 \mathrm{ab}$ & $125 \mathrm{a}$ & $46 \mathrm{bc}$ \\
\hline USDA 115 & 38 & $101 \mathrm{de}$ & $26 \mathrm{e}$ & $114 a b c$ & $37 \mathrm{~d}$ \\
\hline USDA 117 & 76 & $114 \mathrm{bcd}$ & 33 bcde & $118 a b c$ & $38 \mathrm{~cd}$ \\
\hline USDA 122 & 122 & 106 cde & 36 bcd & $110 \mathrm{bc}$ & $40 \mathrm{bcd}$ \\
\hline USDA 123 & 123 & $114 \mathrm{bcd}$ & 35 bcde & $125 \mathrm{ab}$ & $43 \mathrm{bcd}$ \\
\hline USDA 124 & 124 & $96 \mathrm{e}$ & $31 \mathrm{cde}$ & $110 b c$ & $38 \mathrm{~cd}$ \\
\hline USDA 125 & 125 & $131 \mathrm{a}$ & $43 \mathrm{a}$ & $128 \mathrm{a}$ & $47 \mathrm{~b}$ \\
\hline USDA 126 & 125 & $115 \mathrm{bcd}$ & $41 \mathrm{ab}$ & $11 \mathrm{~d}$ & $119 \mathrm{a}$ \\
\hline USDA 130 & 130 & 108 cde & 35 bcde & $109 \mathrm{bc}$ & $36 \mathrm{~d}$ \\
\hline USDA 134 & 38 & $101 \mathrm{de}$ & $28 \mathrm{e}$ & $108 \mathrm{dc}$ & $35 \mathrm{~d}$ \\
\hline USDA 135 & 135 & $107 \mathrm{cde}$ & $30 \mathrm{de}$ & $113 a b c$ & $39 \mathrm{bcd}$ \\
\hline USDA 136 & 122 & $126 \mathrm{ab}$ & $39 a b c$ & $126 \mathrm{~A}$ & $46 \mathrm{bc}$ \\
\hline UMR $161^{z}$ & & $118 \mathrm{bcd}$ & $38 \mathrm{ab}$ & $12 \mathrm{D}$ & $126 \mathrm{a}$ \\
\hline \multicolumn{2}{|c|}{ None (uninoculated control) } & $0 \mathrm{f}$ & $0 \mathrm{f}$ & $0 \mathrm{e}$ & $0 \mathrm{e}$ \\
\hline
\end{tabular}

tive ones (as defined by Vest et al. 1973) with PI 437153A. Approximately $10 \%$ of the ineffective nodules formed were larger and more normal in appearance, but remained white inside with the formation of a deteriorating central region and no apparent sign of leghemoglobin at 35 days after inoculation (DAI). Nodule dry weight (NDW) was approximately 10-fold less and nodule number approximately threefold higher in plants that were ineffectively nodulated.

The 21 strains evaluated represented 15 Bradyrhizobium serogroups, including two strains from serogroup 125 (Table 1). Ineffective nodulation did not occur with both strains from this serogroup; strain USDA 125 nodulated PI 437153A normally. The serogroup classification for UMR 161 remains undefined.

\section{Inheritance of the ineffective-nodulation phenotype.}

A single, dominant gene appears to control ineffective nodulation in PI 437153A. Thus, UMR 161-inoculated $F_{2}$ plants of a cross between PI 437153A and cv. Lambert segregated three plants with ineffective nodulation and one plant with normal nodulation (Table 2). The same segregation ratio and chi-square probability were obtained when a different set of $\mathrm{F}_{2}$ plants were inoculated with USDA 126. Twenty normally nodulated $\mathrm{F}_{2}$ plants from the $\mathrm{cv}$. Lambert $\times$ PI $437153 \mathrm{~A}$ cross had the same phenotype and did not segregate in the $\mathrm{F}_{3}$ generation. Eleven of $20 \mathrm{~F}_{2}$ plants with an ineffectivenodulation phenotype segregated ( 3 ineffective nodulation: 1 normal nodulation) in the $F_{3}$ generation, again suggesting a single, dominant gene.

\section{Grafting results.}

Reciprocal grafting tested whether ineffective nodulation of PI 437153A is controlled by the root or shoot (scion). Ineffective nodulation occurred when plants in which PI 437153A was used as both shoot and root, or as the root stock alone, were inoculated with UMR 161 (Table 3). All grafted plants showed normal nodulation, NDW, and nodule number when inoculated with USDA 110. This indicates that ineffective nodulation in PI 437153A is controlled by the root genotype. The NDWs and nodule numbers of grafted plants exhibiting the ineffective-nodulation phenotype were 10-fold less and threefold more, respectively, than grafted plants exhibiting the effective-nodulation phenotype. The grafting procedure itself had no influence on nodulation, as can be seen from results

Table 2. Nodulation reaction of one $F_{2}$ soybean population and respective parents inoculated with two Bradyrhizobium japonicum strains measured 35 days after inoculation

\begin{tabular}{|c|c|c|c|c|}
\hline \multirow{2}{*}{$\begin{array}{l}\text { Population / } \\
\text { parent }\end{array}$} & \multirow[b]{2}{*}{ Strain } & \multicolumn{2}{|c|}{$\begin{array}{l}\text { Observed } F_{2} \text { nodula- } \\
\text { tion (no. of plants) }\end{array}$} & \multirow{2}{*}{$\underset{\text { probability }}{\chi^{2}}$} \\
\hline & & Normal & Ineffective $^{y}$ & \\
\hline $\begin{array}{c}\text { Cv. Lambert } \times \\
\text { PI 437153A }\end{array}$ & UMR 161 & 40 & 115 & 0.90 to 0.75 \\
\hline Cv. Lambert & UMR 161 & 5 & 0 & $\mathrm{NA}^{\mathrm{z}}$ \\
\hline PI 437153A & UMR 161 & 0 & 5 & NA \\
\hline $\begin{array}{c}\text { Cv. Lambert } \times \\
\text { PI 437153A }\end{array}$ & USDA 126 & 42 & 120 & 0.90 to 0.75 \\
\hline Cv. Lambert & USDA 126 & 5 & 0 & NA \\
\hline PI 437153A & USDA 126 & 0 & 5 & NA \\
\hline
\end{tabular}

${ }^{y}$ Many small, white nodules formed on the ineffective plants, but no normal, pink nodules developed.

${ }^{\mathrm{z}}$ Not applicable. 
obtained with the Lambert/Lambert and PI 437153A/PI 437153A grafts (Table 3).

\section{Effect of temperature and inoculant concentration on the ineffective-nodulation phenotype.}

Incubation temperature affected the nodule number and dry weight of cv. Lambert inoculated with USDA 110, USDA 126, and UMR 161, and of PI 437153A inoculated with B. japonicum strain USDA 110 (Table 4). NDW and nodule number were reduced by 50 to $65 \%$ under low $\left(20^{\circ} \mathrm{C}\right)$ and high $\left(30^{\circ} \mathrm{C}\right)$ incubation temperatures, compared with values obtained at $25^{\circ} \mathrm{C}$. However, when PI 437153A was inoculated with USDA 126 or UMR 161, NDW was not significantly affected, though nodule number was reduced 20 to $30 \%$ at 20 or $30^{\circ} \mathrm{C}$. Incubation temperature did not appear to affect the morphology of ineffective nodules.

Inoculant concentration had no effect on NDW of PI 437153A plants that had been inoculated with UMR 161 or USDA 126 although, at $10^{4}$ and $10^{5}$ cells per ml, nodule number was reduced by $30 \%$ compared with that obtained at $10^{6}$, $10^{7}$, and $10^{8}$ cells per ml. Inoculant concentration significantly affected nodule number and NDW of PI 437153A plants inoculated with USDA 110 and of cv. Lambert plants inoculated with USDA 110, USDA 126, or UMR 161. NDW and nodule number were reduced by 20 to $70 \%$ at $10^{4}, 10^{5}$, or $10^{8}$ cells per ml, compared with values obtained at $10^{6}$ or $10^{7}$ cells per $\mathrm{ml}$ (data not shown).

Table 3. Nodule dry weight (NDW) and nodule number (No.) of grafted and ungrafted soybean genotypes inoculated with Bradyrhizobim japonicum USDA 110 and UMR 161 harvested 35 days after inoculation ${ }^{\mathrm{y}}$

\begin{tabular}{lccccr}
\hline \multirow{2}{*}{$\begin{array}{l}\text { Soybean genotype } \\
\text { (shoot / root) }\end{array}$} & \multicolumn{2}{c}{ USDA 110 } & & \multicolumn{2}{c}{ UMR 161 } \\
\cline { 2 - 3 } \cline { 6 - 6 } & NDW (mg) & No. & & NDW (mg) & No. \\
\hline Cv. Lambert (ungrafted) & $106 \mathrm{a}^{\mathrm{z}}$ & $38 \mathrm{a}$ & & $121 \mathrm{a}$ & $36 \mathrm{~b}$ \\
PI 437152A (ungrafted) & $110 \mathrm{a}$ & $43 \mathrm{a}$ & & $10 \mathrm{~b}$ & $122 \mathrm{a}$ \\
Lambert / Lambert & $102 \mathrm{a}$ & $35 \mathrm{a}$ & $111 \mathrm{a}$ & $38 \mathrm{~b}$ \\
PI 437153A / PI 437153A & $97 \mathrm{a}$ & $35 \mathrm{a}$ & $9 \mathrm{~b}$ & $108 \mathrm{a}$ \\
Lambert / PI 437153A & $107 \mathrm{a}$ & $40 \mathrm{a}$ & & $7 \mathrm{~b}$ & $110 \mathrm{a}$ \\
PI 437153A / Lambert & $101 \mathrm{a}$ & $39 \mathrm{a}$ & & $106 \mathrm{a}$ & $34 \mathrm{~b}$ \\
\hline
\end{tabular}

${ }^{\mathrm{y}}$ NDW and No. values are expressed on a per plant basis.

${ }^{z}$ Values within columns followed by different letters are significantly different at the $P<0.05$ level based on a protected least significant digit.

Table 4. Nodule dry weight (NDW) and nodule number (No.) of two soybean genotypes inoculated with Bradyrhizobium japonicum USDA 110, USDA 126, and UMR 161 grown at three temperatures and harvested 35 days after inoculation ${ }^{y}$

\begin{tabular}{|c|c|c|c|c|c|c|}
\hline \multirow[b]{2}{*}{$\begin{array}{l}\text { Soybean genotype / } \\
\text { temperature }\end{array}$} & \multicolumn{2}{|c|}{ USDA 110} & \multicolumn{2}{|c|}{ USDA 126} & \multicolumn{2}{|c|}{ UMR 161} \\
\hline & $\begin{array}{c}\text { NDW } \\
(\mathrm{mg})\end{array}$ & No. & $\begin{array}{c}\text { NDW } \\
(\mathrm{mg})\end{array}$ & No. & $\begin{array}{c}\text { NDW } \\
(\mathbf{m g})\end{array}$ & No. \\
\hline \multicolumn{7}{|l|}{ Cv. Lambert } \\
\hline $20^{\circ} \mathrm{C}$ & $53 \mathrm{~b}^{\mathrm{z}}$ & $21 \mathrm{~b}$ & $49 \mathrm{~b}$ & $24 \mathrm{~b}$ & $52 \mathrm{~b}$ & $23 \mathrm{~b}$ \\
\hline $25^{\circ} \mathrm{C}$ & $118 \mathrm{a}$ & $41 \mathrm{a}$ & $102 \mathrm{a}$ & $37 \mathrm{a}$ & $102 \mathrm{a}$ & $39 a$ \\
\hline $30^{\circ} \mathrm{C}$ & $38 \mathrm{~b}$ & $24 \mathrm{~b}$ & $42 \mathrm{~b}$ & $28 \mathrm{~b}$ & $43 \mathrm{~b}$ & $26 \mathrm{~b}$ \\
\hline \multicolumn{7}{|l|}{ PI 437153A } \\
\hline $20^{\circ} \mathrm{C}$ & $46 \mathrm{~b}$ & $19 \mathrm{~b}$ & $9 \mathrm{a}$ & $98 \mathrm{~b}$ & $11 \mathrm{a}$ & $91 \mathrm{~b}$ \\
\hline $25^{\circ} \mathrm{C}$ & $106 \mathrm{a}$ & $41 \mathrm{a}$ & $9 \mathrm{a}$ & $121 \mathrm{a}$ & $10 \mathrm{a}$ & $127 \mathrm{a}$ \\
\hline $30^{\circ} \mathrm{C}$ & $39 \mathrm{~b}$ & $21 \mathrm{~b}$ & $10 \mathrm{a}$ & $86 \mathrm{~b}$ & $9 \mathrm{a}$ & $78 \mathrm{~b}$ \\
\hline
\end{tabular}

${ }^{y}$ NDW and No. values are expressed on a per plant basis.

${ }^{z}$ Values within columns and genotypes followed by different letters are significantly different at the $P<0.05$ level based on a protected least significant digit.
Nodule activity and protein concentration of the ineffective-nodulation phenotype.

NDW, acetylene reduction activity (ARA), nodule soluble protein concentration (SOLP), and leghemoglobin concentration (Lb) did not differ among the four normally nodulating genotype-strain combinations (Table 5). In contrast, when PI 437153A was inoculated with either UMR 161 or USDA 126, there was an approximately 10 -fold reduction in NDW and a four- to fivefold decrease in nodule SOLP. No ARA or Lb was detected in the ineffective nodules. The $10 \%$ of the nodules that were larger and appeared more normal in appearance also had low SOLP (9.5 $\mu$ g of protein per mg of NFW) and no detectable $\mathrm{Lb}$ when separately analyzed. Additionally, no changes in nodule appearance were detected, even when the incubation period was extended until 60 DAI.

\section{Expression levels of PAL and CHS transcript.}

CHS and PAL transcript levels increased 2 to 6 DAI in both PI 437153A inoculated with USDA 110 and cv. Lambert inoculated with UMR 161, compared with the uninoculated control (Fig. 1). The CHS transcript levels in PI 437153A roots inoculated with UMR 161 did not differ from those of the other genotype-strain combinations tested. However, there was a striking increase in PAL transcript levels at 2 to 6 DAI in PI 437153A plants inoculated with UMR 161 (Fig. 1; lanes L, M, and N).

\section{Microscopic analysis of the ineffective-nodulation phenotype.}

There were striking differences in the ultrastructure of effective and ineffective nodules sectioned 20 DAI. Normal nodules (Fig. 2, panels A, B) show typical soybean structure. The infected and uninfected cells of the $\mathrm{N}_{2}$-fixing region are surrounded by an inner cortex containing nodule vascular bundles. External to these cells is a single layer of thickwalled schlerenchyma cells (red staining), with the nodule cortex comprising the outer layer of nodule cells. By comparison, ineffective nodules sampled 20 DAI had centrally located vascular bundles, surrounded by schlerenchyma (Fig. 2, panels C-F) Schlerenchyma cells were also found scattered throughout the nodules. Most of the cells in the ineffective nodules resemble uninfected cortical cells.

Two distinct ineffective nodule types were evident on PI

Table 5. Nodule dry weight (NDW), acetylene reduction activity (ARA), nodule soluble protein concentration (SOLP), and leghemoglobin concentration (Lb) of two soybean genotypes inoculated with three Bradyrhizobium japonicum strains harvested 35 days after inoculation

\begin{tabular}{llcccc}
\hline Genotype & \multicolumn{1}{c}{ Strain } & $\begin{array}{c}\text { NDW } \\
(\mathbf{m g} / \mathbf{p l a n t})\end{array}$ & $\begin{array}{c}\text { ARA } \\
(\boldsymbol{\mu m o l} \\
\mathbf{C}_{2} \mathbf{H}_{4} / \mathbf{h} / \\
\mathbf{p l a n t})\end{array}$ & $\begin{array}{c}\text { SOLP } \\
(\boldsymbol{\mu g} \text { pro- } \\
\text { tein) }^{\mathbf{y}}\end{array}$ & $\begin{array}{c}\mathbf{L b} \\
(\boldsymbol{\mu g ~ L b} \\
\text { protein })^{\mathbf{y}}\end{array}$ \\
\hline Cv. Lambert & USDA 110 & $118 \mathrm{a}^{\mathrm{z}}$ & $8.6 \mathrm{a}$ & $37.5 \mathrm{a}$ & $13.2 \mathrm{a}$ \\
& UMR 161 & $127 \mathrm{a}$ & $7.9 \mathrm{a}$ & $41.2 \mathrm{a}$ & $14.4 \mathrm{a}$ \\
PI 437153A A & USDA 126 & $111 \mathrm{a}$ & $8.2 \mathrm{a}$ & $37.8 \mathrm{a}$ & $12.6 \mathrm{a}$ \\
& USDA 110 & $112 \mathrm{a}$ & $10.1 \mathrm{a}$ & $42.1 \mathrm{a}$ & $13.6 \mathrm{a}$ \\
& UMR 161 & $12 \mathrm{~b}$ & $0 \mathrm{~b}$ & $8.4 \mathrm{~b}$ & $0 \mathrm{~b}$ \\
& USDA 126 & $13 \mathrm{~b}$ & $0 \mathrm{~b}$ & $9.1 \mathrm{~b}$ & $0 \mathrm{~b}$ \\
\hline
\end{tabular}

${ }^{y}$ Per milligram of nodule fresh weight (NFW).

${ }^{z}$ Values within columns followed by different letters are significantly different at the $P<0.05$ level based on a protected least significant digit. All values are the average of all nodules collected. 
437153A plants, 35 DAI. Approximately $90 \%$ of these were small, white, cortical proliferations, similar to the ones noted 20 DAI. The remainder were larger and had a structure similar to an effective nodule. However, two striking features distinguish these ineffective nodules from effective ones at 35 DAI (Fig. 2G and H). First, there appears to be a region of infected cells that do not have $\mathrm{N}_{2}$-fixing activity. Second, there are large, deteriorating, central regions in the middle of these nodules. Figure $2 \mathrm{H}$ shows an apparently infected cell, although appearing smaller than the normal infected cells of Figure 2B (same magnification), near numerous uninfected cells. Additionally, Figure $2 \mathrm{H}$ shows a cluster of very tightly compacted, small cells with small nuclei in the deteriorating central region. No deteriorating regions were found in the effective nodules 35 DAI, suggesting that nodule senescence had not yet begun (figures not included).

\section{DISCUSSION}

Single host genes differentially restricting nodulation with specific strains of $B$. japonicum have been identified in a number of soybean cultivars (Caldwell 1966; Caldwell et al. 1966; Vest 1970; Vest and Caldwell 1972; Cregan et al. 1989; Lohrke et al. 1996; Qian et al. 1996). The work reported in this paper had as its aim a better understanding of the genetic, physiological, and morphological mechanisms controlling the ineffective nodulation of the soybean PI 437153A with B. japonicum UMR 161 (Pazdernik et al. 1996).

Our study clearly demonstrates that ineffective nodulation of PI 437153A occurs with at least two B. japonicum strains, and that this phenotype is conditioned by a single, dominant gene. This is believed to be the first reported case of ineffective nodulation within serogroup 125 , but not all strains within this group responded similarly when used to inoculate PI 437153A. Additional serogroups, and additional strains from serogroup 125 , will need to be evaluated to precisely identify the limits of ineffective nodulation with PI 437153A.

The ineffective nodulation reported here is apparently due to a host gene different from those considered in earlier studies. It is not governed by $\mathrm{Rj}_{1}, \mathrm{Rj}_{5}$, or $\mathrm{Rj}_{6}$, which condition a restricted nodulation phenotype with all bradyrhizobia (Williams and Lynch 1954; Pracht et al. 1993), and does not appear related to $\mathrm{Rj}_{2}, \mathrm{Rj}_{3}$, or $\mathrm{Rj}_{4}$. PI 437153A nodulated normally with USDA 122 and USDA 136 (serogroup 122),
USDA 33, and USDA 61 (Caldwell 1966; Vest 1970; Vest and Caldwell 1972). Strains from serogroup c1 were not included in this study, and should be investigated to completely rule out the $\mathrm{Rj}_{2}$ gene. Future research should also investigate allelisms and linkages between the gene controlling the ineffective nodulation in PI 437153A and previously identified restriction genes $\left(\mathrm{Rj}_{1}\right.$ through $\left.\mathrm{Rj}_{6}\right)$.

Ineffective nodulation between PI 437153A and USDA 161 is controlled by the genotype of the soybean root and is independent of any shoot factor(s). This is consistent with other restricted- and nonnodulation genetic systems (Caldwell et al. 1966; Balatti and Pueppke 1992; Sadowsky et al. 1995).

Our study and others have considered the effect nonhost factors have on nodulation and $\mathrm{N}_{2}$ fixation. Ferrey et al. (1994) studied several restricted host-strain pairs in soybean and found large differences in nodulation ability as a function of inoculant cell concentration. They concluded that nodulation restriction was not absolute, but appeared due to differences in nodulation efficiency that could be overcome by altering inoculant cell concentration. This does not seem to be the case with PI 437153A, as only minor changes resulted with increasing inoculation concentration of USDA 126 or UMR 161.

Incubation temperature has also been shown to affect hostcontrolled nodulation restriction. Sadowsky et al. (1995) concluded that nodulation restriction was dependent on plant growth temperature in the PI 377578-USDA 438 and PI 377578-USDA 61 systems. In contrast to the previous authors's conclusions, incubation temperature had only a minor affect on the ineffective nodulation of the PI 437153AUMR 161 and PI 437153A-USDA 126 systems. The fact that the $25^{\circ} \mathrm{C}$ growing temperature resulted in more nodules for both the ineffective- and normal-nodulation phenotypes may be due to the $25^{\circ} \mathrm{C}$ temperature being close to the optimum temperature for soybean growth, and not to any real effect on the ineffective phenotype.

An interesting feature of nodule development in the PI 437153A-UMR 161 and PI 437153A-USDA 126 systems was the enhanced number of nodules formed per root, coupled with a lack of $\mathrm{N}_{2}$-fixing activity. Novak et al. (1995) described a pea mutant that hypernodulated but had highly reduced ARA and $\mathrm{Lb}$, and postulated that this response could be due to the absence of a nodule-derived, short-range regulatory factor in contrast to a shoot factor.

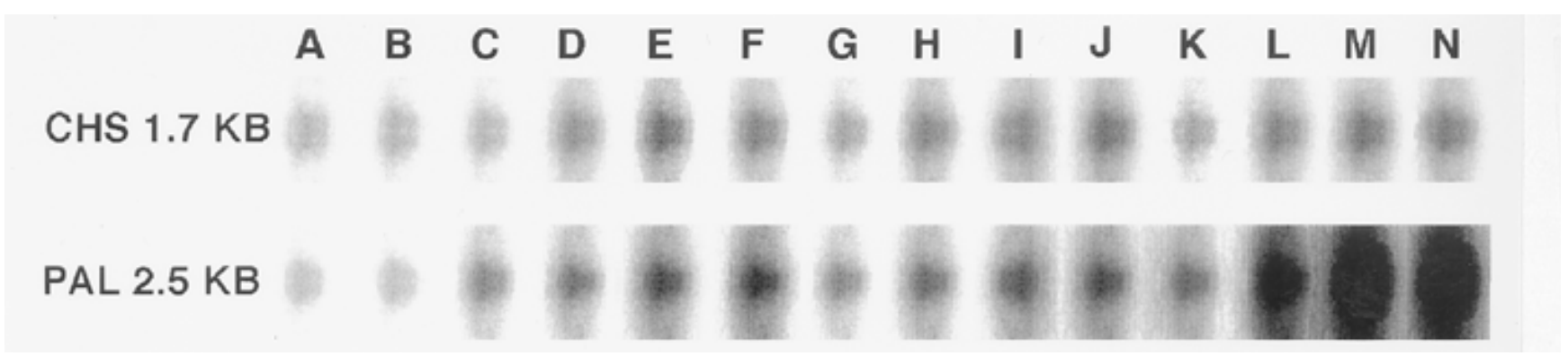

Fig. 1. RNA gel blot analysis of total RNA isolated from roots of two soybean genotypes and two Bradyrhizobium japonicum strains for chalcone synthase (CHS) and phenylalanine ammonia-lyase (PAL). Lanes: A, cv. Lambert uninoculated harvested 10 days after planting (DAP) ; B, PI 437153A uninoculated harvested 10 DAP; C, D, E, and F, PI 437153A inoculated with strain USDA 110 harvested 1, 2, 4, and 6 days after inoculation (DAI), respectively; G, H, I, and J, cv. Lambert inoculated with strain UMR (University of Minnesota Rhizobium) 161 harvested 1, 2, 4, and 6 DAI, respectively; and K, L, M, and N, PI 437153A inoculated with strain UMR 161 harvested 1, 2, 4, and 6 DAI, respectively. All inoculated plants were inoculated 4 DAP. 

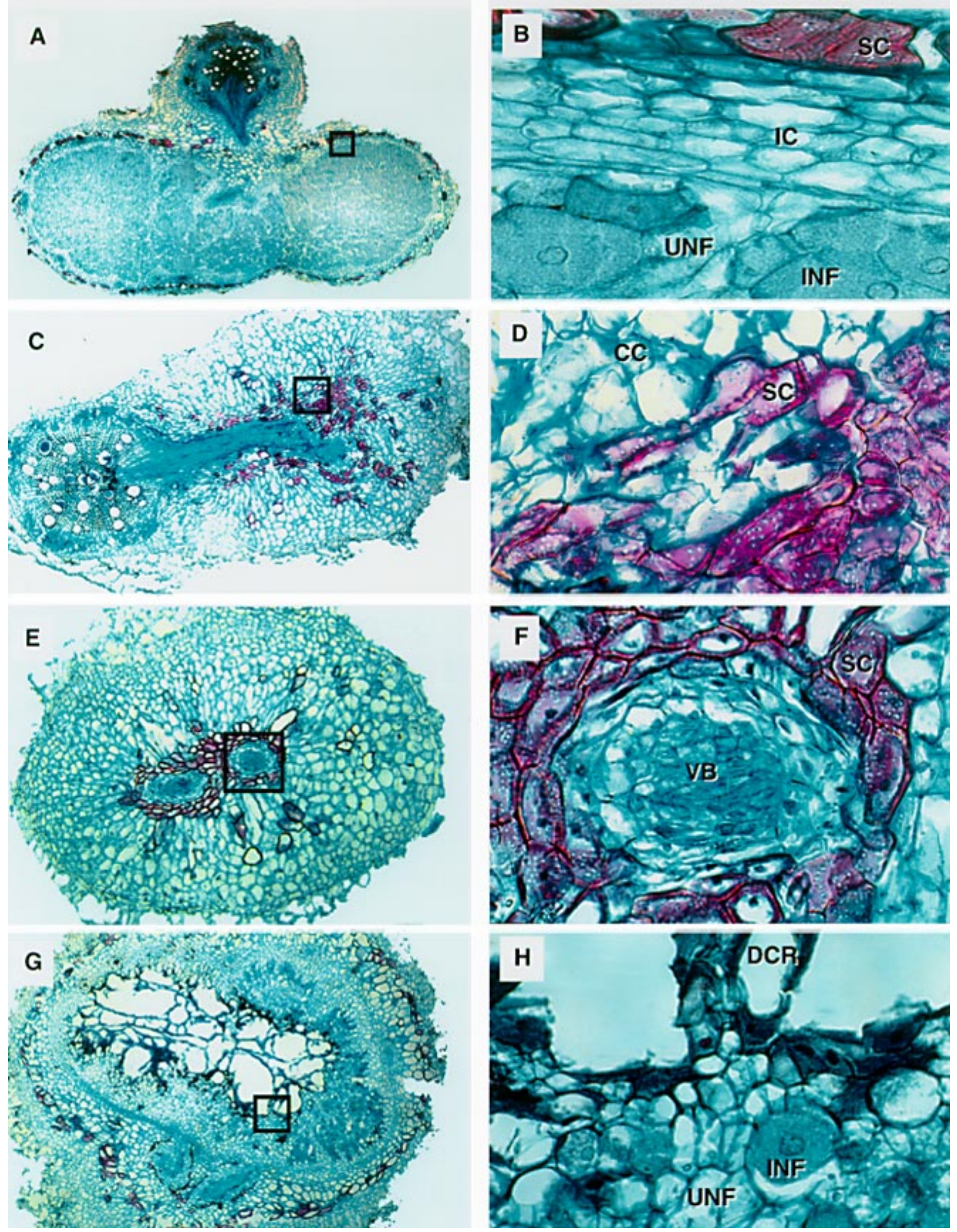
The difference in PAL transcript levels during infection in the PI 437153A-UMR 161 nodulation system could be due to several different factors. Estabrook and Sengupta-Gopalan (1991) suggested that an increase in PAL and CHS transcript levels in the supernodulating mutant nts 382 might be due to an increased number of infections, as also found in the system studied here. Another possibility is that incompatibility between PI 437153A and UMR 161 could result in the triggering of plant defense responses. The development of necrotic tissues in the large ineffective nodules produced 35 DAI is suggestive of incompatibility between host and rhizobia, while the red staining of the unorganized schlerenchyma cells (Fig. $2 \mathrm{C}$ and $\mathrm{D}$ ) is suggestive of lignin deposition. Lignin synthesis would be accompanied by increased PAL levels, but would not require expression of CHS. This is consistent with the results obtained in this study. Plant defense response has also been suggested in the Risfix $\mathrm{V}$ pea mutant (Novak et al. 1995), in the Vicia faba L. symbiosis-induced phytoalexin production mutant (Wolff and Werner 1990), and in a compatible/incompatible interaction of B. japonicum USDA 123 with Glycine soja (Parniske et al. 1990). Werner et al. (1985) showed the accumulation of glyceollin during infection by some $\mathrm{Nod}^{+} \mathrm{Fix}^{-}$bacteria, and future studies should assess whether glyceollin or other related compounds accumulate in the PI 437153A-UMR 161 ineffective-nodulation system. We need also to compare the surface chemistry of USDA 126 and UMR 161 with that of other strains, and to more precisely study initial infection events.

\section{MATERIALS AND METHODS}

\section{Methodologies for the evaluation of 21 Bradyrhizobium strains with two soybean genotypes in Leonard jars.}

The nodulation of 21 Bradyrhizobium strains (USDA 125, USDA 136, USDA 110, USDA 123, USDA 61, USDA 33, USDA 28, USDA 44, USDA 117, USDA 4, USDA 115, USDA 46, USDA 135, USDA 122, USDA 124, USDA 130, USDA 134, USDA 62, USDA 94, USDA 126, and UMR 161) with cv. Lambert and PI 437153A was tested with modified Leonard jar assemblies (Vincent 1970) containing vermiculite and silica sand (2:1). Strain UMR 161 was previously described by McDermott and Graham (1989). Seeds of each genotype were surface sterilized with $95 \%$ (vol/vol) ethanol and $3 \%$ (vol/vol) sodium hypochlorite (Vincent 1970) and rinsed repeatedly in sterile water. Seeds were planted, watered with half-strength, nitrogen-free nutrient solution (McDermott and Graham 1990), inoculated, and covered with a 1-cm layer of sterilized, paraffin-coated sand. The inoculant was prepared as described elsewhere (Pazdernik et al. 1996) with $10 \mathrm{ml}$ applied $\left(10^{6}\right.$ cells per $\left.\mathrm{ml}\right)$ per Leonard jar. Seedlings were thinned to two seedlings per Leonard jar 2 days after emergence. Three Leonard jars were not inoculated and served as negative controls. Plants were maintained in a Conviron PGW36 growth chamber (Controlled Environment, Winnipeg, Canada) with a 16 -h photoperiod and $25 / 22^{\circ} \mathrm{C}$ day/night temperature. Thirty-five DAI, plants were harvested, the phenotype of each host-strain interaction noted, and the nodule number and NDW determined. The experiment was analyzed as a randomized complete block with three replications, two plants per Leonard jar equaling one replication. The analysis was performed with the analysis of variance (ANOVA) procedure within SAS, version 6.03 (SAS/STAT Guide for Personal Computers, SAS Institute, Cary, NC). A protected lsd (least significant digit) at the $P<0.05$ level was then used to differentiate among individual treatments.

\section{Ineffective-nodulation inheritance test procedure.}

Individual $\mathrm{F}_{2}$ and subsequent $\mathrm{F}_{3}$ plants from the cross PI $437153 \mathrm{~A} \times \mathrm{cv}$. Lambert were planted in modified Leonard jar assemblies and inoculated with either $B$. japonicum strain UMR 161 or USDA 126, as described above. Nodulation reactions were recorded at $35 \mathrm{DAI}$ as either normal or ineffective. One hundred fifty-five $F_{2}$ plants were inoculated with strain UMR 161 and $162 \mathrm{~F}_{2}$ plants were tested with USDA 126. Twenty random $F_{2}$ plants from each nodule phenotype were advanced to the $F_{3}$ generation and tested (five $F_{3}$ plants per $F_{2}$ plant) for confirmation of the $F_{2}$ phenotype and segregation pattern. Five Leonard jars of each parent-strain combination were used as controls. All plants were grown under the same growth chamber conditions as described above. Chisquare analysis was used to test the single-gene hypothesis.

\section{Grafting methodology.}

Reciprocal grafting (Albertsen et al. 1983) was performed between cv. Lambert and PI 437153A to determine if the ineffective-nodulation phenotype was root or shoot controlled. Five seeds per genotype were planted in Leonard jar assemblies as previously described, then thinned to three seedlings per genotype 3 days after emergence (DAE). Reciprocal grafts between two seedlings of cv. Lambert and PI 437153A were made in each Leonard jar 4 DAE. One ungrafted cv. Lambert plant and one ungrafted PI 437153A plant were included in each Leonard jar to serve as controls. Intra-genotypic grafts in separate Leonard jars were made to serve as additional controls. All plants were inoculated with either B. japonicum strain USDA 110 or UMR 161 immediately following grafting and grown under the same growth chamber conditions as previously described. At 35 DAI, plants were scored for nodulation phenotype with number and NDW determined. Ten plants (five Leonard jars equaling five replications) of each graft

Fig. 2. Light microscopy of normal- and ineffective-nodule phenotypes of PI 437153A inoculated with either Bradyrhizobium japonicum strain USDA 110 or UMR (University of Minnesota Rhizobium) strain 161. A, Overview of 2 normal effective nodules developed from USDA 110. B, Close-up of (A) showing normal infected and uninfected cells, inner cortex, and sclerenchymatous cells at 20 days after inoculation (DAI). C, Overview of a longitudinal section through ineffective-nodule phenotype from UMR 161. D, Close-up of (C) showing unorganized, red sclerenchymatous cells and cortical cells without infected cells at 20 DAI. E, Overview of a cross-section through ineffective nodule phenotype from UMR 161. F, Close-up of (E) showing sclerenchymatous cells and vascular bundle without infected cells at 20 DAI. G, Overview of a ineffective nodule phenotype from UMR 161 . H, Closeup of $(\mathbf{G})$ showing apparent infected and uninfected cells near a large, deteriorating, central region at $35 \mathrm{DAI}$. CC $=$ cortical cells; DCR = deteriorating central region; IC = inner cortex; INF = infected cells; $\mathrm{SC}=$ sclerenchymatous cells; UNF = uninfected cells; VB = vascular bundle. Magnifications: $\mathbf{A}$, $\times 40 ; \mathbf{C}, \mathbf{E}$, and $\mathbf{G}, \times 100$; and $\mathbf{B}, \mathbf{D}, \mathbf{F}$, and $\mathbf{H}, \times 1,000$. 
type were used to confirm the results. The analysis was performed with the ANOVA procedure within SAS. A protected lsd at the $P<0.05$ level was then used to differentiate among individual treatments.

\section{Procedure to test growth temperature and inoculant concentration on the ineffective-nodulation phenotype.}

Leonard jar assemblies containing two plants per jar and inoculated with either B. japonicum strain USDA 110, USDA 126 , or UMR 161 (as previously described) were used to investigate the effect of growth temperature on the ineffectivenodulation phenotype in three separate temperature experiments. Uninoculated plants served as negative controls. Plants were grown at 20,25 , or $30^{\circ} \mathrm{C}$ under the same growth chamber conditions as previously described. Nodule phenotype, NDW, and nodule number were recorded at 35 DAI. Each temperature experiment was conducted twice (two replications) with five Leonard jars per treatment used in each experiment. The analysis was performed with the ANOVA procedure within SAS. A protected lsd at the $P<0.05$ level was then used to differentiate among individual treatments.

The effect of inoculant concentration on the ineffective nodulation phenotype was also investigated with Leonard jar assemblies. Leonard jars containing two plants per jar were inoculated with $10 \mathrm{ml}$ of $B$. japonicum strain USDA 110, USDA 126 , or UMR 161 at five concentrations $\left(10^{4}, 10^{5}, 10^{6}, 10^{7}\right.$, and $10^{8}$ cells per $\mathrm{ml}$ ). Uninoculated plants served as negative controls. Nodule phenotype, NDW, and number were recorded at 35 DAI. The entire experiment was conducted twice (two replications) with two Leonard jars per treatment used in each replication. The analysis was performed with the ANOVA procedure within SAS. A protected lsd at the $P<0.05$ level was then used to differentiate among individual treatments.

\section{Procedures used to investigate $\mathrm{N}_{2}$ fixation and protein concentration.}

Lambert and PI 437153A were inoculated with $B$. japonicum strains UMR 161, USDA 126, and USDA 110 and separately evaluated for NDW and ARA, and for SOLP and Lb. Additionally, the larger, more normal appearing ineffective nodules (approximately 10\%) from the PI 437153A-UMR 161 and PI 437153A-USDA 126 combinations were separately analyzed for nodule SOLP and Lb. Leonard jar assemblies and growth chamber conditions were as previously described with nodules harvested 35 DAI.

Plants were harvested and assayed for nitrogenase activity by an acetylene reduction procedure similar to that described by Dart et al. (1975), but with an incubation period of only 10 min, which effectively removes error due to inhibition of nitrogenase by acetylene. Nodules were picked, dried, and weighed, and NDW recorded.

Nodule soluble protein and Lb concentrations were measured by homogenizing $100 \mathrm{mg}$ of fresh nodules at $4^{\circ} \mathrm{C}$ in $1 \mathrm{ml}$ of $\beta$-mercaptoethanol extraction buffer, $\mathrm{pH} 6.8$, then centrifuging at $18,000 \times g$ for $15 \mathrm{~min}$ at $4^{\circ} \mathrm{C}$ to remove cells and debris. Nodule SOLP was determined by the method of Bradford (1976), with bovine serum albumin as a standard. Leghemoglobin was determined through immunoblots by loading $5 \mu \mathrm{g}$ of total nodule soluble protein onto lanes of a sodium dodecyl sulfate polyacrylamide gel $(12 \%)$, electrophoresing, transferring to nitrocellulose membranes, and probing with leghemoglobin antibody (previously developed in the laboratory of Carroll Vance). Leghemoglobin concentrations were then determined with a densitometer, with pure leghemoglobin A (courtesy of Robert Klucas, Lincoln, NE) used for standardization and quantification.

Each experiment was analyzed as a two-factor (genotype and strain), randomized complete block design with four replications, each consisting of two plants. The analysis was performed with the ANOVA procedure within SAS. A protected lsd at the $P<0.05$ level was then used to differentiate among individual treatments.

\section{Procedures for PAL and CHS transcript analysis.}

Transcript levels of PAL and CHS in the ineffectivenodulation and normal-nodulation phenotypes were evaluated with growth pouches (Mega International, Minneapolis, MN). Ten milliliters $\left(10^{4}\right.$ cells per $\left.\mathrm{ml}\right)$ of B. japonicum USDA 110 or UMR 161 was applied to each growth pouch and the position of each root tip at the time of inoculation (RTM) marked (Bhuvaneswari et al. 1980, 1981). Root segments ( $2 \mathrm{~cm}$ each) were harvested on either side of the RTM at 1,2, 4, and 6 DAI. Uninoculated plants were used as negative controls. Twenty growth pouches (two plants per pouch) were used for each treatment, and growth chamber conditions were as previously described.

Total RNA isolation from the root segments and RNA gel blotting were as described elsewhere (Gantt et al. 1992) with $15 \mu \mathrm{g}$ of total root RNA per lane. Ethidium bromide staining was used to ensure equal loading in each lane. The resulting filters were hybridized with random primed, ${ }^{32} \mathrm{P}$-labeled PAL $(1.43 \mathrm{~kb})$ and CHS $(1.10 \mathrm{~kb})$ probes (courtesy of Champa Sengupta-Gopalan, Las Cruces, NM). Hybridization and washing of blots were as described by Gregerson et al. (1993). Radioactivity on blots was quantified with an AMBIS Radioanalytic Imaging System (San Diego, CA). Following quantitation, filters were placed on X-ray film for autoradiography. Two RNA gels and blots each for PAL and CHS were run to test repeatability.

\section{Light microscopy protocol.}

Nodules from cv. Lambert and PI 437153A, inoculated with either B. japonicum USDA 110 or UMR 161, were collected at 20 and 35 DAI, respectively, from plants grown in Leonard jar assemblies in the growth chamber as previously described.

Nodules were fixed overnight in $4 \%$ paraformaldehyde and

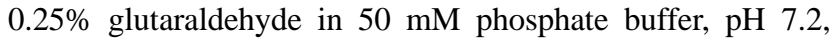
then rinsed in the same solution, and dehydrated in a graded ethanol series, and the ethanol replaced with xylene through another graded series. The nodules were embedded in Paraplast Plus Tissue Embedding Medium (Oxford Labware, St. Louis, MO) at $60^{\circ} \mathrm{C}$ over a 3-day time span. The embedded nodules were sectioned ( $9 \mu \mathrm{m}$ thick) and affixed to poly-Llysine-coated slides. The embedding medium was removed from the sections through xylene treatments. The sections were then stained with safranin and fast-green (Jensen 1962) and analyzed by light-field microscopy.

\section{ACKNOWLEDGMENTS}

This work was supported in part by a grant from the Minnesota Department of Agriculture and Minnesota Soybean Research and Promo- 
tion Council. This is a joint contribution of the Plant Science Research Service Unit, U.S. Department of Agriculture, Agriculture Research Service, and the Minnesota Agricultural Experiment Station.

\section{LITERATURE CITED}

Albertsen, M. C., Curry, T. M., Palmer, R. G., and Lamotte, C. E. 1983 Genetics and comparative growth morphology of fasciation in soybeans [Glycine max (L.) Merr.]. Bot. Gaz. 144:263-275.

Balatti, P. A., and Pueppke, S. G. 1992. Differential sensitivity of Rhizobium fredii strains to nodulation blocking on McCall soybean: Nodulation rates and efficiency. Plant Physiol. Biochem. 30:193-199.

Bhuvaneswari, T. V., Bhagwat, A. A., and Bauer, W. D. 1981. Transient susceptibility of root cells in four common legumes to nodulation by rhizobia. Plant Physiol. 68:1144-1149.

Bhuvaneswari, T. V., Turgeon, B. G., and Bauer, W. D. 1980. Early events in the infection of soybean (Glycine $\max$ L. Merr.) by Rhizobium japonicum. Plant Physiol. 66:1027-1031.

Bradford, M. M. 1976. A rapid and sensitive method for the quantitation of microgram quantities of protein utilizing the principle of proteindye binding. Anal. Biochem. 72:248-254.

Caldwell, B. E. 1966. Inheritance of a strain-specific ineffective nodulation in soybeans. Crop Sci. 6:427-428.

Caldwell, B. E., Hinson, K., and Johnson, H. W. 1966. A strain-specific ineffective nodulation reaction in the soybean Glycine max L. Merrill. Crop Sci. 6:495-496.

Cregan, P. B., and Keyser, H. H. 1986. Host restriction of nodulation by Bradyrhizobium japonicum strain USDA 123 in soybean. Crop Sci. 26:911-916.

Cregan, P. B., Keyser, H. H., and Sadowsky, M. J. 1989. Soybean genotype restricting nodulation of a previously unrestricted serocluster 123 bradyrhizobia. Crop Sci. 29:307-312.

Dart, P. N. J., Day, J. M., and Harris, D. 1975. Assay for nitrogenase activity by acetylene reduction. IAEA Tech. Rep. 149:85-100.

Delves, A. C., Matthews, A., Day, D. A., Carter, A. S., Carroll, B. J., and Gresshoff, P. M. 1986. Regulation of the soybean-Rhizobium symbiosis by shoot and root factors. Plant Physiol. 82:588-590.

Devine, T. E., and O'Neill, J. J. 1989. Genetic allelism of nodulation response genes $\mathrm{Rj}_{1}, \mathrm{Rj}_{2}$, and $\mathrm{Rj}_{4}$ in soybean. Crop Sci. 29:1347-1350.

Devine, T. E., and O'Neill, J. J. 1993. Genetic independence of the nodulation-response gene loci $-\mathrm{Rj}_{1}, \mathrm{Rj}_{2}$, and $\mathrm{Rj}_{4}$ - in soybean. $\mathrm{J}$. Hered. 84:140-142.

Estabrook, E. M., and Sengupta-Gopalan, C. 1991. Differential expression of phenylalanine ammonia-lyase and chalcone synthase during soybean nodule development. Plant Cell 3:299-308.

Ferrey, M. L., Graham, P. H., and Russelle, M. P. 1994. Nodulation efficiency of Bradyrhizobium japonicum strains with genotypes of soybean varying in the ability to restrict nodulation. Can. J. Microbiol. 40:456-460.

Gantt, S. J., Larson, R. J., Farnham, M. W., Pathirana, S. M., Miller, S. S., and Vance, C. P. 1992. Aspartate aminotransferase in effective and ineffective alfalfa nodules. Cloning of a cDNA and determination of enzyme activity, protein, and mRNA levels. Plant Physiol. 98:868878.

Gregerson, R. G., Miller, S. S., Twary, S. N., Gantt, J. S., and Vance, C. P. 1993. Molecular characterization of NADH-dependent glutamate synthase from alfalfa nodules. Plant Cell 5:215-226.

Ham, G. E. 1978. Interactions of Glycine max and Rhizobium japonicum. Pages 289-296 in: Advances in Legume Science. R. J. Summer- field and A. H. Bunting, eds. Royal Botanic Gardens, Kew, England.

Jensen, W. A. 1962. Botanical Histochemistry. W. H. Freeman, San Francisco.

Johnson, J. W., Means, U. M., and Weber, C. R. 1965. Competition for nodule sites between strains of Rhizobium japonicum applied as inoculum and strains in the soil. Agron. J. 57:179-185.

Lohrke, S. M., Orf, J. H., Martines-Romero, E., and Sadowsky, M. J. 1995. Host-controlled restriction of nodulation by Bradyrhizobium japonicum strains in serogroup 110. Appl. Environ. Microbiol. 61: 2378-2383.

Lohrke, S. M., Orf, J. H., and Sadowsky, M. J. 1996. Inheritance of hostcontrolled restriction of nodulation by Bradyrhizobium japonicum strain USDA 110. Crop Sci. 36:1271-1276.

McDermott, T. R., and Graham, P. H. 1989. Bradyrhizobium japonicum inoculant mobility, nodule occupancy, and acetylene reduction in the soybean root system. Appl. Environ. Microbiol. 55:2493-2498.

McDermott, T. R., and Graham, P. H. 1990. Competitive ability and efficiency in nodule formation of strains of Bradyrhizobium japonicum. Appl. Environ. Microbiol. 56:3035-3039.

Novak, K., Pesina, K., Nebesarova, J., Skrdleta, V., Lisa, L., and Nasinec, V. 1995. Symbiotic tissue degradation pattern in the ineffective nodules of three nodulation mutants of pea (Pisum sativum L.). Ann. Bot. (Lond.) 76:303-313.

Parniske, M., Zimmermann, C., Cregan, P. B., and Werner, D. 1990. Hypersensitive reaction of nodule cells in the Glycine sp./Bradyrhizobium japonicum symbiosis occurs at the genotype-specific level. Bot. Acta 103:143-148.

Pazdernik, D. P., Graham, P. H., Vance, C. P., and Orf, J. H. 1996. Host genetic variation in the early nodulation and dinitrogen fixation of soybean. Crop Sci. 36:1102-1107.

Pracht, J. E., Nickell, C. D., and Harper, J. E. 1993. Genes controlling nodulation in soybean: $\mathrm{Rj}_{5}$ and $\mathrm{Rj}_{6}$. Crop Sci. 33:711-713.

Qian, D., Allen, F. L., Stacey, G., and Gresshoff, P. M. 1996. Plant genetic study of restricted nodulation in soybean. Crop Sci. 36:243-249.

Sadowsky, M. J., and Cregan, P. B. 1992. The soybean $\mathrm{Rj}_{4}$ allele restricts nodulation by Bradyrhizobium japonicum serogroup 123 strains. Appl. Environ. Microbiol. 58:720-723.

Sadowsky, M. J., Kosslak, R. M., Madrzak, C. J., Golinska, B., and Cregan, P. B. 1995. Restriction of nodulation by Bradyrhizobium japonicum is mediated by factors present in the roots of Glycine max. Appl. Environ. Microbiol. 61:832-836.

Vest, G. 1970. $\mathrm{Rj}_{3}$ - a gene conditioning ineffective nodulation in soybean. Crop Sci. 10:34-35.

Vest, G., and Caldwell, B. E. 1972. $\mathrm{Rj}_{4}$ - a gene conditioning ineffective nodulation in soybean. Crop Sci. 12:692-693.

Vest, G., Weber, D. F., and Sloger, C. 1973. Nodulation and nitrogen fixation. In: Soybeans: Improvement, Production, and Uses. B. E. Caldwell, ed. Agronomy 16:353-390.

Vincent, J. M. 1970. A manual for the practical study of root nodule bacteria. Int. Biol. Prog. Handb. 15. Blackwell Scientific Pub., Oxford.

Werner, D., Mellor, R. B., Hahn, M. G., and Grisebah, H. 1985. Soybean root response to symbiotic infection: Glyceollin I accumulation in an ineffective type of soybean nodules with an early loss of the peribacteroid membrane. Z. Naturforsch. 40c:179-181.

Williams, L. F., and Lynch, D. L. 1954. Inheritance of a nonnodulating character in a soybean. Agron. J. 46:28-29.

Wolff, A. B., and Werner, D. 1990. Defence reactions of Rhizobiumlegume symbiosis: Phytoalexin concentration in Vicia faba nodules is affected by the host plant genotype. Z. Naturforsch. 45c:958-962. 